\title{
Identification and Spoilage Potential of the Remaining Dominant Microbiota on Food Contact Surfaces after Cleaning and Disinfection in Different Food Industries
}

\author{
SHARON MAES, ${ }^{1}$ MARC HEYNDRICKX, ${ }^{1,2}$ THIJS VACKIER, ${ }^{3}$ HANS STEENACKERS, ${ }^{4}$ ALEX VERPLAETSE, ${ }^{3}$ \\ AND KOEN DE REU ${ }^{1 *}$
}

\begin{abstract}
${ }^{1}$ Flanders Research Institute for Agriculture, Fisheries and Food, Technology and Food Science Unit, Brusselsesteenweg 370, 9090 Melle, Belgium; ${ }^{2}$ Department of Pathology, Bacteriology and Poultry Diseases, Faculty of Veterinary Medicine, Ghent University, Salisburylaan 133, 9820 Merelbeke, Belgium; ${ }^{3}$ Laboratory of Enzyme, Fermentation and Brewery Technology, Cluster for Bioengineering Technology, Department of Microbial and Molecular Systems, Faculty of Engineering Technology, University of Leuven, Gebroeders De Smetstraat 1, 9000 Ghent, Belgium; and ${ }^{4}$ Centre of Microbial and Plant Genetics, Department of Microbial and Molecular Systems, Faculty of Bioscience Engineering, University of Leuven, Kasteelpark Arenberg 20 Box 2460, 3001 Leuven, Belgium
\end{abstract}

MS 18-226: Received 23 May 2018/Accepted 9 October 2018/Published Online 25 January 2019

\begin{abstract}
After cleaning and disinfection (C\&D), surface contamination can still be present in the production environment of food companies. Microbiological contamination on cleaned surfaces can be transferred to the manufactured food and consequently lead to foodborne illness and early food spoilage. However, knowledge about the microbiological composition of residual contamination after C\&D and the effect of this contamination on food spoilage is lacking in various food sectors. In this study, we identified the remaining dominant microbiota on food contact surfaces after C\&D in seven food companies and assessed the spoilage potential of the microbiota under laboratory conditions. The dominant microbiota on surfaces contaminated at $\geq 10^{2}$ CFU/100 $\mathrm{cm}^{2}$ after C\&D was identified based on $16 \mathrm{~S}$ rRNA sequences. The ability of these microorganisms to hydrolyze proteins, lipids, and phospholipids, ferment glucose and lactose, produce hydrogen sulfide, and degrade starch and gelatin also was evaluated. Genera that were most abundant among the dominant microbiota on food contact surfaces after C\&D were Pseudomonas, Microbacterium, Stenotrophomonas, Staphylococcus, and Streptococcus. Pseudomonas spp. were identified in five of the participating food companies, and $86.8 \%$ of the isolates evaluated had spoilage potential in the laboratory tests. Microbacterium and Stenotrophomonas spp. were identified in five and six of the food companies, respectively, and all tested isolates had spoilage potential. This information will be useful for food companies in their quest to characterize surface contamination after $C \& D$, to identify causes of microbiological food contamination and spoilage, and to determine the need for more thorough $\mathrm{C} \& \mathrm{D}$.
\end{abstract}

Key words: Identification; Pseudomonas spp; Spoilage; Surface contamination

Standard operating procedures, among which are regular cleaning and disinfection $(\mathrm{C} \& \mathrm{D})$, are developed and used in the food industry to eliminate foodborne pathogens and to reduce contamination with spoilage organisms to acceptable levels in the production environment. Despite these measures, surface contamination after C\&D in food processing facilities still occurs $(35,36)$. Microbiological contamination on cleaned surfaces can be transferred to the manufactured food and can lead to foodborne illness when pathogens are present $(1,2,9,22)$. Most foodborne outbreaks reported in the European Union in 2016 were caused by Salmonella (responsible for 65.8\% of all bacteria-associated outbreaks) and Campylobacter (28.3\%), with 9,061 and 4,606 affected individuals, respectively (14). Early food spoilage can be caused by

\footnotetext{
* Author for correspondence. Tel: +329272 30 43; Fax: +32 927230 01; E-mail: koen.dereu@ilvo.vlaanderen.be.
}

residual spoilage organisms (or their spores) on food contact surfaces. Bacillus and Pseudomonas species are known spoilage organisms in dairy products $(11,26,34,38)$, and lactic acid bacteria (LAB) shorten the shelf life of meat products $(5,15,34)$. Biofilms containing pathogenic or spoilage microorganisms can cause or maintain contamination on surfaces or food products $(6,15,21,23)$.

In a previous study (24), residual contamination on food contact surfaces after C\&D was mapped and characterized in terms of bacterial levels and chemical composition. Bacterial contamination after $C \& D$ of food contact surfaces ranged from $<0.22$ to $7.23 \log \mathrm{CFU} / 100$ $\mathrm{cm}^{2}$ (mean \pm standard deviation of $3.62 \pm 1.20 \mathrm{log}$ CFU/ $100 \mathrm{~cm}^{2}$ ) on contaminated surfaces. However, information about the microbiological composition of this residual contamination after $\mathrm{C} \& \mathrm{D}$ and the importance of this contamination for food spoilage in various food sectors is lacking. 
TABLE 1. Food companies and food contact surfaces sampled on one to three sampling occasions ${ }^{a}$

\begin{tabular}{|c|c|c|c|c|c|}
\hline \multirow[b]{2}{*}{ Food company } & \multirow[b]{2}{*}{ Food products } & \multirow{2}{*}{$\begin{array}{l}\text { No. of } \\
\text { surfaces } \\
\text { sampled }^{b}\end{array}$} & \multirow{2}{*}{$\begin{array}{l}\text { No. of surfaces from } \\
\text { which isolates were recovered }\end{array}$} & \multicolumn{2}{|c|}{$\begin{array}{l}\text { No. of isolates } \\
\text { recovered }\end{array}$} \\
\hline & & & & PCA & $\mathrm{PAB}$ \\
\hline \multirow[t]{2}{*}{ Oven food } & \multirow{2}{*}{$\begin{array}{l}\text { Ready-to-heat products (e.g., } \\
\text { croquettes, lasagna, puff } \\
\text { pastry bites) }\end{array}$} & 11 & $\begin{array}{l}4 \text { ( } 2 \text { conveyor belts, } 2 \text { parts of the } \\
\text { filling system) }\end{array}$ & 30 & 0 \\
\hline & & 11 & $\begin{array}{l}8 \text { (3 conveyor belts, } 5 \text { parts of the } \\
\text { filling system) }\end{array}$ & 65 & 0 \\
\hline \multirow[t]{2}{*}{ Dairy 1} & Milk powder & 10 & $\begin{array}{l}4 \text { (pasteurizer, evaporator, } 2 \\
\text { manifolds) }\end{array}$ & 49 & 7 \\
\hline & Ice cream, cheese, butter & 13 & 2 (capacitor, homogenizer) & 6 & 0 \\
\hline Dairy 2 & $\begin{array}{l}\text { Whipped cream, other } \\
\text { pasteurized dairy products }\end{array}$ & 6 & 3 (pipe, sterilizer, storage tank) & 10 & 0 \\
\hline \multirow[t]{2}{*}{ Meat 1} & \multirow[t]{2}{*}{ Cooked ham, pâté } & 8 & $\begin{array}{l}3 \text { ( } 2 \text { parts of the brining line, } \\
\text { rinsing device) }\end{array}$ & 11 & 0 \\
\hline & & 15 & $\begin{array}{c}5 \text { ( } 3 \text { parts of the brining line, } 2 \\
\text { parts of the rinsing device) }\end{array}$ & 38 & 0 \\
\hline \multirow[t]{3}{*}{ Meat 2} & \multirow[t]{3}{*}{$\begin{array}{l}\text { Cooked ham, cooked sausage, } \\
\text { pâté }\end{array}$} & 20 & $\begin{array}{l}6 \text { ( } 4 \text { conveyor belts, knife of a } \\
\text { slicing line, rack })\end{array}$ & 62 & 24 \\
\hline & & 20 & $\begin{array}{l}6 \text { ( } 4 \text { conveyor belts, knife of a } \\
\text { slicing line, table) }\end{array}$ & 28 & 22 \\
\hline & & 17 & 0 & 0 & 0 \\
\hline \multirow[t]{2}{*}{ Egg processing } & \multirow[t]{2}{*}{$\begin{array}{l}\text { Pasteurized egg products (e.g., } \\
\text { whole egg, egg yolk, egg } \\
\text { whites) }\end{array}$} & 11 & $\begin{array}{l}4 \text { ( } 2 \text { parts of the egg breaker, } \\
\text { collection container, conveyor } \\
\text { belt) }\end{array}$ & 32 & 4 \\
\hline & & 11 & $\begin{array}{l}7 \text { (part of the egg breaker, } \\
\text { conveyor belt, stirring tool, } 2 \\
\text { storage tanks, } 2 \text { parts of the } \\
\text { filling system) }\end{array}$ & 35 & 12 \\
\hline \multirow[t]{3}{*}{ Sauce } & \multirow{3}{*}{$\begin{array}{l}\text { Hot and cold sauces (e.g., } \\
\text { mayonnaise, bolognaise, } \\
\text { pickles) }\end{array}$} & 5 & 2 (2 parts of the filling system) & 21 & 0 \\
\hline & & 5 & 3 (3 parts of the filling system) & 20 & 0 \\
\hline & & 7 & 0 & 0 & 0 \\
\hline
\end{tabular}

${ }^{a}$ Isolates were collected from contaminated surfaces after C\&D and recovered on plate count agar (PCA) and Pseudomonas agar base (PAB) with Pseudomonas CFC selective agar supplement.

${ }^{b}$ Microbiological enumeration and chemical analyses were previously described by Maes et al. (24).

${ }^{c}$ A random selection of the samples with TACs $\geq 10^{2} \mathrm{CFU} / 100 \mathrm{~cm}^{2}$ was used for identification of the dominant flora.

In the present study, the dominant bacteria remaining on food contact surfaces after C\&D in several food companies were collected and further characterized. The isolates were identified by $16 \mathrm{~S}$ rRNA sequencing, and their occurrence in the companies was studied. Because bacteria on food contact surfaces can be transferred to food products, these isolates also were assessed under laboratory conditions to estimate their role in food spoilage.

\section{MATERIALS AND METHODS}

Sampling and microbiological contamination of surfaces in food companies. This study was conducted with samples collected in a previous study (24). The samples were taken from several surfaces in seven Belgian food companies after C\&D (producers of oven foods, meat products, sauces, and egg products) or after cleaning (producers of dairy products) (Table 1). The parts of the production line that were in contact with food, such as conveyor belts, pipelines, storage tanks, and trolleys, were sampled during two sampling periods, and samples were evaluated for their microbiological load and chemical composition. In that study, total aerobic counts (TACs) ranged from $<0.22$ to $7.23 \mathrm{log}$ $\mathrm{CFU} / 100 \mathrm{~cm}^{2}$. For three food companies (dairy company 1 , meat company 2, and the egg processing company), Pseudomonas spp. were also enumerated, and counts were in the same range as the TACs. Proteins were found in $20 \%$ of the chemically analyzed surface samples $(n=165)$, and carbohydrates and uronic acids were found in 15 and $8 \%$ of the samples, respectively. When chemical and microbiological results were combined, $17 \%$ of the sampled surfaces in the seven food companies appeared to be contaminated with both a high number of microorganisms $\left(\geq 10^{2}\right.$ $\mathrm{CFU} / 100 \mathrm{~cm}^{2}$ ) and at least one of the analyzed chemical components, which can indicate the presence of biofilms (24).

Microbiological characterization of surface contamination. (i) Isolate collection. Following microbiological and chemical analysis of the samples conducted in the previous study (24), a random selection of microbiological contaminated food contact surfaces $\left(n=57\right.$; TAC $\left.\geq 10^{2} \mathrm{CFU} / 100 \mathrm{~cm}^{2}\right)$ were further characterized in the present study by focusing on the dominant flora. Pseudomonas levels were determined, and isolates were recovered on Pseudomonas agar base (PAB; CM0559, Oxoid, Basingstoke, UK) and Pseudomonas CFC selective agar supplement (SR0103, Oxoid) $(n=16)$. The plates with the highest serial 10-fold dilutions in which growth occurred represented the dominant microbiota. Based on morphology, 2 to 17 colonies were selected from plate count agar (PCA; CM0325, Oxoid), and 1 to 8 colonies were selected from $\mathrm{PAB}$ for each of the 
contaminated surface samples. Colonies were streaked and incubated on new PCA plates at least three times to obtain pure cultures. The pure cultures were inoculated into brain heart infusion broth (CM1135, Oxoid) with $15 \%$ glycerol (8.18709.1000, Merck, Darmstadt, Germany), incubated for 2 days at $30^{\circ} \mathrm{C}$, and stored at $-80^{\circ} \mathrm{C}$.

A total of 407 isolates from surface samples after C\&D were recovered on PCA and 69 on PAB (Table 1). Isolates were classified into three bacterial abundance classes. For isolates recovered on PCA, classes were $<3 \log$ CFU/100 $\mathrm{cm}^{2}$ (low bacterial levels), 3 to $5 \log \mathrm{CFU} / 100 \mathrm{~cm}^{2}$ (medium levels), and $>5$ $\log \mathrm{CFU} / 100 \mathrm{~cm}^{2}$ (high levels). For isolates recovered on PAB, the classes were $2 \log$ CFU/100 $\mathrm{cm}^{2}$ (low level), 2 to $4 \log \mathrm{CFU} / 100$ $\mathrm{cm}^{2}$ (medium level), and $>4 \log \mathrm{CFU} / 100 \mathrm{~cm}^{2}$ (high level).

(ii) Identification of the isolates. From each isolate, except those that could not be cultivated after storage at $-80^{\circ} \mathrm{C}$ ( 35 of the 476 isolates), DNA was collected according to the method of Strandén et al. (39). DNA extracts were stored at $4^{\circ} \mathrm{C}$ and used on the same day for (GTG) $)_{5}$ PCR as described by Maes et al. (25) for clustering of the isolates. Of the 441 isolates included in the $(\mathrm{GTG})_{5}$ fingerprint clusters, 327 were selected for identification based on the their patterns as representatives of visually defined clusters. For clusters with two or three isolates, one isolate was selected to identify the complete cluster. For clusters with four or more isolates, a minimum of two isolates were selected for identification. The 16S rRNA gene was amplified for identification of the selected isolates according to the method of Maes et al. (25). PCR products were sequenced by Macrogen Europe (Amsterdam, The Netherlands). Sequence reads of $\geq 500 \mathrm{bp}$ were used for further analysis in EzTaxon (20). The species in the database with the highest similarity (minimum of $98.5 \%$ ) and completeness was used to assign the isolates to a putative species. When different species with the same similarity and completeness level were found for an isolate, these isolates were identified to genus only. In total, 16S rRNA sequencing led to the identification of 281 of the 327 isolates. With the (GTG) $)_{5}$ fingerprint results, a total of 382 of the 476 isolates were identified to genus or species.

(iii) Evaluation of the spoilage potential of the isolates. For isolates that were successfully identified from growth on PCA and $\mathrm{PAB}$, spoilage potential was evaluated under laboratory conditions. All isolates were evaluated for their potential to hydrolyze proteins, lipids, or phospholipids. Other spoilage tests (production of hydrogen sulfide, fermentation of lactose and glucose, and degradation of starch and gelatin) were performed on a limited number of isolates, depending on the type of product manufactured in each company (Table 2).

To evaluate the spoilage potential, the selected isolates were recultivated on PCA plates from the glycerol stocks held at $-80^{\circ} \mathrm{C}$. A positive control was included for each spoilage test and each batch of tested isolates. For the evaluation of proteolysis, isolates were streaked on PCA plates with $17 \%(\mathrm{v} / \mathrm{v})$ skimmed milk and incubated at $30^{\circ} \mathrm{C}$ for 3 days. Isolates were evaluated as positive for proteolysis when a clear zone appeared around colonies. Lipolysis was evaluated by cultivating the isolates on tributyrin agar (PM0004C, Oxoid) for 3 days at $30^{\circ} \mathrm{C}$. A positive result was defined as a clear zone around the colonies. Nutrient agar (CM0003, Oxoid) with 8\% (v/v) egg yolk (SR0047, Oxoid) was used for evaluation of phospholipolysis based on the method of Price et al. (33). Inoculated plates were incubated at $30^{\circ} \mathrm{C}$ for 3 days, and a positive result was indicated by a precipitation zone. For evaluation of hydrogen sulfide production, isolates were smeared on the surface of slant tubes of Kligler iron agar
(CM0033, Oxoid) and stabbed into the butt of the tube with a microloop. Tubes were incubated at $30^{\circ} \mathrm{C}$ and evaluated after 24 and $48 \mathrm{~h}$. A positive result was visible as black staining. Glucose and lactose fermentation were evaluated using bromcresol purple broth (36408-500G, Sigma-Aldrich, Overijse, Belgium) tubes with 0.7\% (w/v) glucose (LP0071, Oxoid) or lactose (LP0070, Oxoid), respectively, and Durham tubes were added. Tested isolates were inoculated into the tubes and incubated for $48 \mathrm{~h}$ at $30^{\circ} \mathrm{C}$. Sugar fermentation was visible as a change in the color of the medium from purple to yellow. Fermentation was accompanied by gas formation in the Durham tube. The ability to degrade starch was evaluated by inoculating the isolates onto starch agar containing 3 $\mathrm{g}$ of Lab-Lemco powder (LP0029, Oxoid), $10 \mathrm{~g}$ of potato starch (Sigma-Aldrich, S4501), and $12 \mathrm{~g}$ of bacteriological agar (LP0011, Oxoid) dissolved in $1 \mathrm{~L}$ of distilled water. After 2 days of incubation at $30^{\circ} \mathrm{C}$, bacterial growth was scraped off, and Lugol solution (L6146, Sigma-Aldrich) was poured over the plates. A positive result was visible as a clear (orange) zone at the height of inoculation. The degradation of gelatin was evaluated in a medium containing $120 \mathrm{~g}$ of gelatin (LP0008, Oxoid), $3 \mathrm{~g}$ of Lab-Lemco powder, and $5 \mathrm{~g}$ of bacteriological peptone (LP0037, Oxoid) dissolved in $1 \mathrm{~L}$ of distilled water and divided into test tubes at 5 $\mathrm{mL}$ per tube. Tubes were inoculated by stabbing the isolate with a microloop into the butt of the tubes. Inoculated tubes were incubated for 7 days at $37^{\circ} \mathrm{C}$ with a blank (noninoculated) tube. Before interpretation of the result, test tubes were held at $7^{\circ} \mathrm{C}$ until the medium in the blank tube was solidified. The medium in the sample tube remained liquid when the isolate was positive for gelatinase production.

General results of the spoilage tests were evaluated in Excel (2016, Microsoft, Redmond, WA). The similarities in spoilage potential of several groups of isolates (e.g., based on the company of origin) were calculated in Bionumerics version 7.6 (Applied Maths, Sint-Martens-Latem, Belgium). Dendrograms were calculated using the Dice coefficient for binary data, and isolates were clustered using the unweighted pair group method with arithmetic means (UPGMA). Minimum spanning trees also were generated for these groups of isolates.

\section{RESULTS}

Identification of microorganisms on surfaces in food processing companies after C\&D. (i) Oven food company. Among the gram-positive bacteria $(n=34)$ collected from PCA plates, the most abundant genus was Microbacterium $(n=14)$ (Fig. 1). Most of the identified gram-positive bacteria were present at medium or high levels. The most commonly identified genus among the gram-negative bacteria $(n=39)$ was Pseudomonas $(n=18)$, which was present at medium or high levels.

(ii) Two dairy companies. Gram-positive bacteria recovered on PCA ( $n=42$ for dairy $1 ; n=8$ for dairy 2) were mostly identified as Streptococcus (at low levels), Microbacterium, Solibacillus, and Dermacoccus in dairy company 1 . For dairy company 2 , all isolates were present at low levels and were identified as Bacillus spp. or Microbacterium lacticum (Fig. 1). Twelve gram-negative bacteria were recovered on PCA in dairy company 1, and Brevundimonas was the most abundant genus. No gramnegative bacteria were identified in dairy company 2 . Seven isolates were recovered on PAB in dairy company 1 (Fig. 


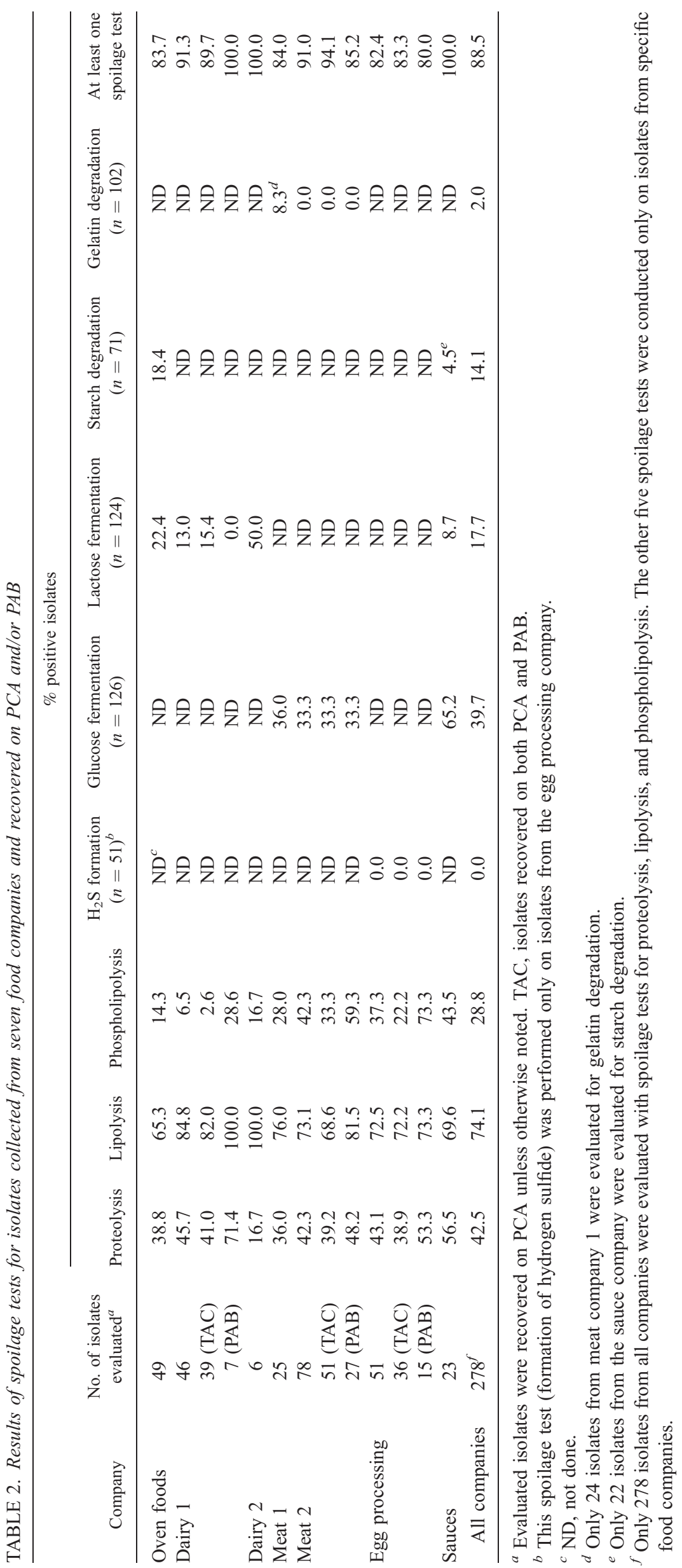




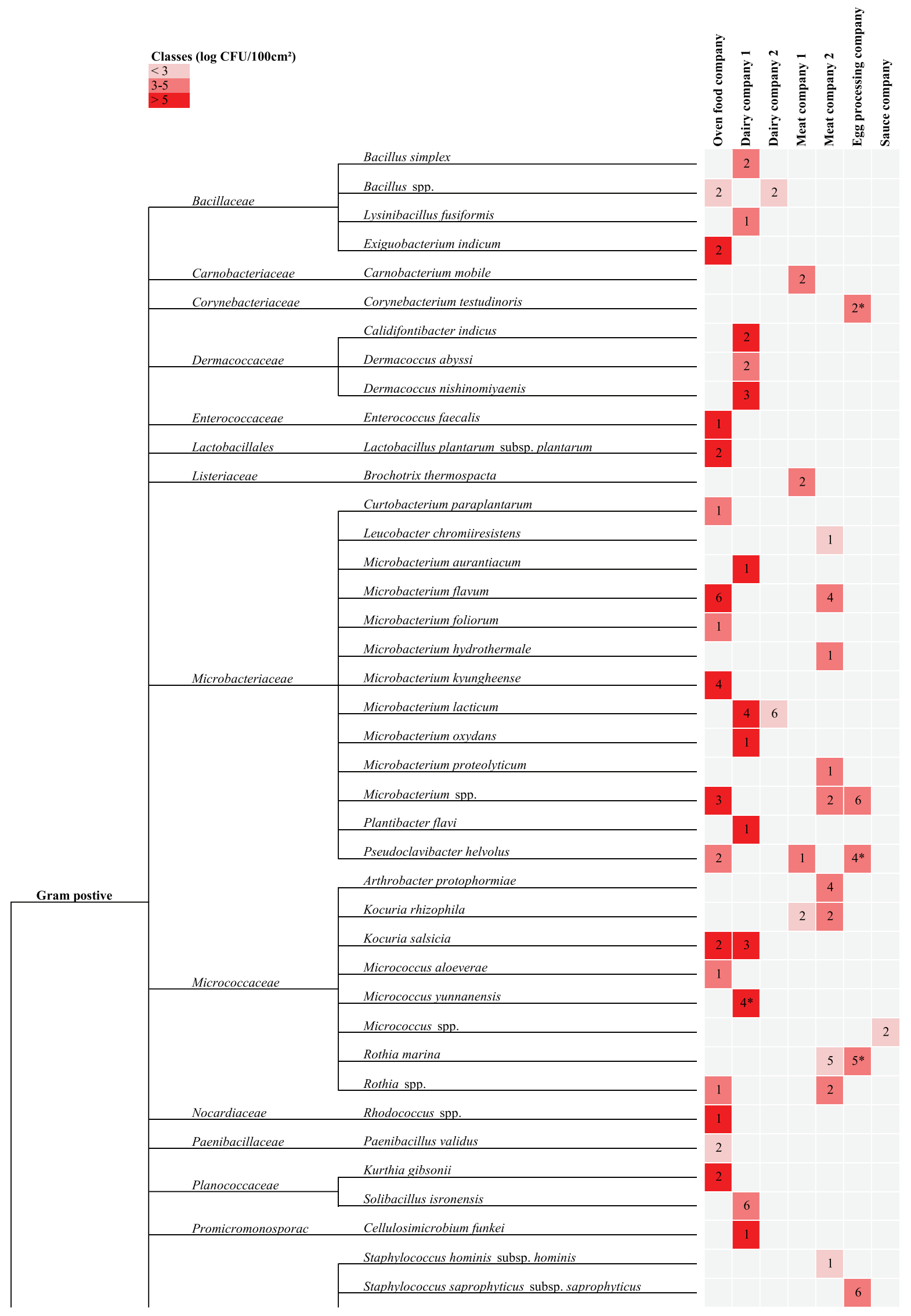

FIGURE 1. Total aerobic bacterial isolates identified to family (http://www.bacterio.net/, verified 12 April 2018), genera, and species after recovery on plate count agar from surface samples collected after cleaning and disinfection in seven food companies. Colors represent the bacterial levels (low, medium, high). An asterisk indicates that the species was found during the first and second sampling round in the same company. 


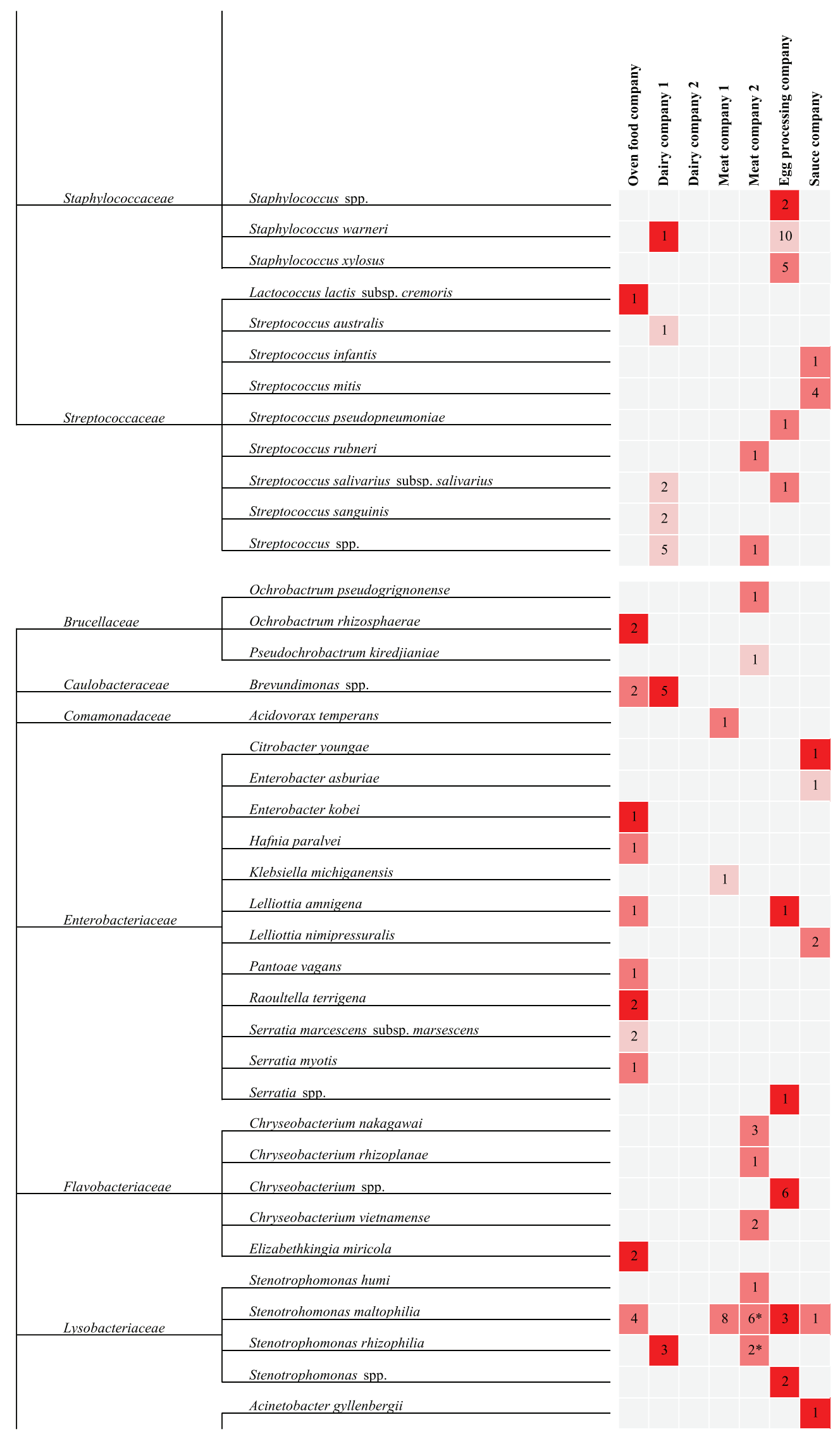

FIGURE 1. Continued. 


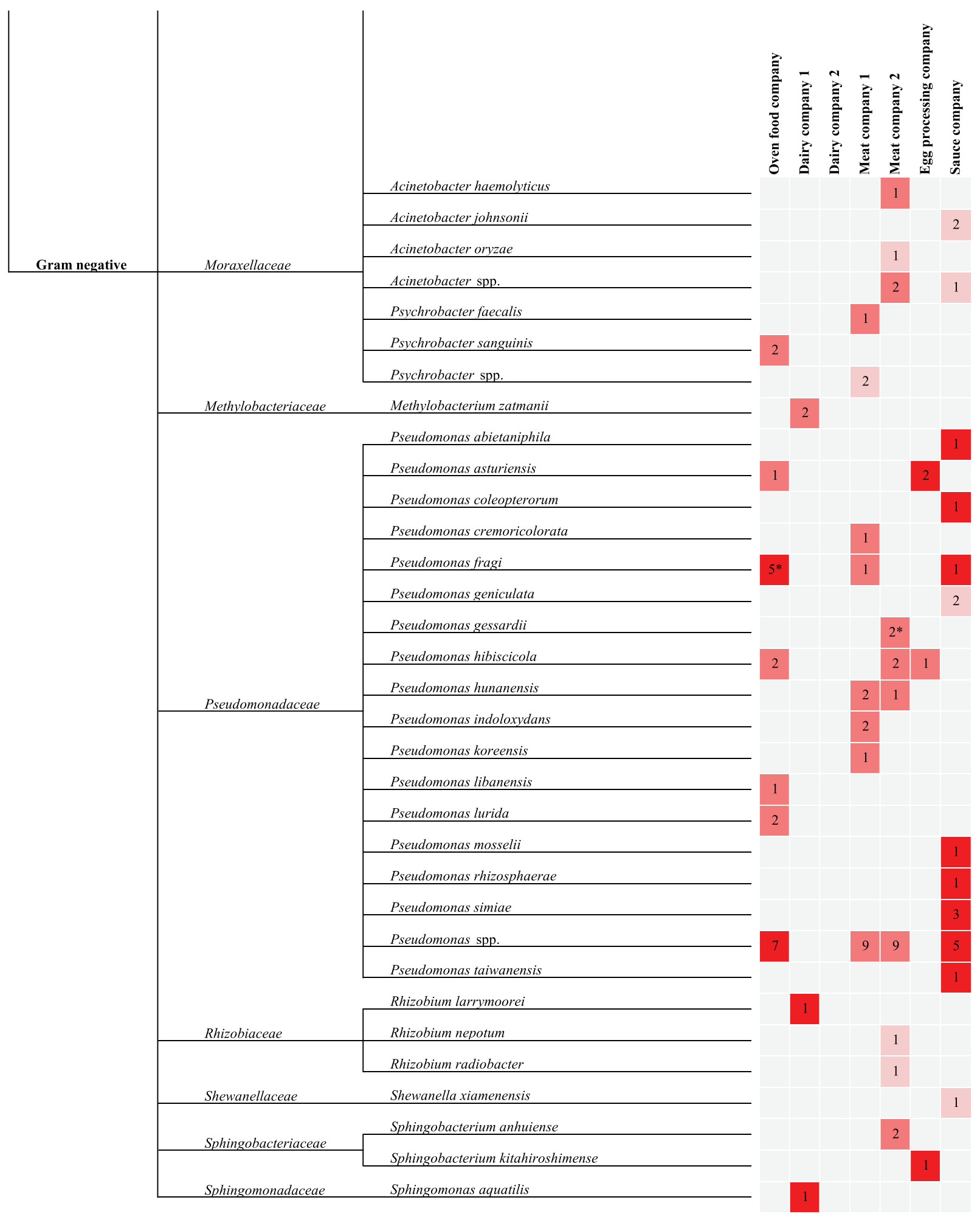

FIGURE 1. Continued.

2): six isolates of Stenotrophomonas rhizophila and one of Pseudomonas hunanensis, both at low levels.

(iii) Two meat companies. Among the gram-positive bacteria recovered on PCA, 7 isolates were found in meat company 1 and 25 were found in meat company 2 (Fig. 1). In meat company 2 , the most commonly identified grampositive bacteria were Microbacterium and Rothia, which were not found in meat company 1 . In meat company 1 , more gram-negative isolates $(n=29)$ than gram-positive isolates $(n=7)$ were recovered on PCA. The dominant gram-negative bacteria identified were Stenotrophomonas and Pseudomonas. TACs were low in both of the meat companies. For meat company 2 , isolates recovered on PAB $(n=33)$ (Fig. 2) were mostly P. hunanensis. 


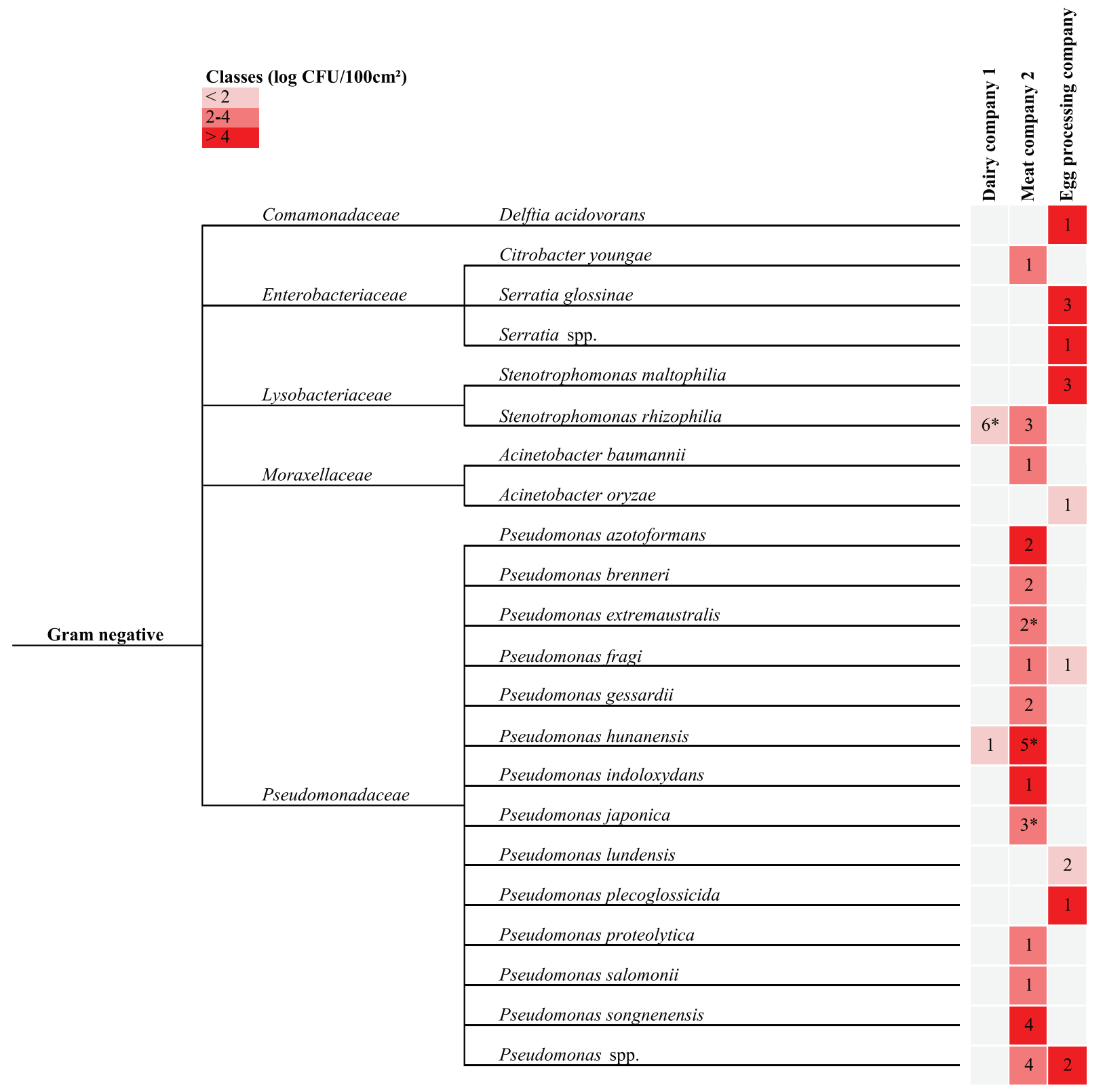

FIGURE 2. Pseudomonas spp. isolates identified to family (http://www.bacterio.net/, verified 12 April 2018), genera, and species after recovery on Pseudomonas agar base (PAB) with Pseudomonas CFC selective agar supplement from surface samples collected after cleaning and disinfection in three food companies. Different colors represent the magnitude of PAB enumerations of samples whereof the bacteria were isolated. Colors represent the bacterial levels (low, medium, high). An asterisk indicates that the species was found during the first and second sampling round in the same company.

(iv) Egg processing company. Most of the identified gram-positive bacteria $(n=42)$ were present at medium levels and were identified as Staphylococcus spp. $(n=23)$ (Fig. 1). For the gram-negative bacteria $(n=17)$, which mostly occurred at high levels, Stenotrophomonas spp. and Pseudomonas spp. were dominant. On PAB, Delftia and Acinetobacter also were identified (Fig. 2).

(v) Sauce company. TACs consisted mostly of gramnegative bacteria (26 isolates versus 7 gram-positive isolates) (Fig. 1). The dominant gram-positive bacteria were Streptococcus $(n=5)$. Most gram-negative bacteria were identified as Pseudomonas spp. $(n=16)$ or Acinetobacter spp. $(n=4)$. (vi) Similarities and differences among isolates from various food sectors. For all sampled food companies, most of the isolates recovered on PCA $(n=327)$ were Pseudomonas (20.5\%), Microbacterium (12.2\%), Stenotrophomonas (9.2\%), Staphylococcus (7.6\%), and Streptococcus $(5.8 \%)$. For isolates that were tentatively classified to species ( $n=247), 8.9 \%$ were identified as Stenotrophomonas maltophilia, $4.5 \%$ as Staphylococcus warneri, and $4.0 \%$ as Microbacterium flavum, M. lacticum, or Rothia marina. The other identified species occurred at $<4.0 \%$. Approximately the same number of gram-positive $(48.6 \%)$ and gramnegative $(51.4 \%)$ bacteria were recovered on PCA. Bacteria isolated from PCA belonged to 50 genera, and $60 \%$ of these isolates were company specific. Isolates recovered on PAB $(n$ 
FIGURE 3. Clustering of spoilage results for isolates from two dairy companies based on UPGMA. Results of the four spoilage tests (proteolysis, lipolysis, phospholipolysis, and lactose fermentation) are shown in order on each branch: 0 indicates a negative result for that test, and 1 indicates a positive result. Groups were based on the genera of the tested isolates.

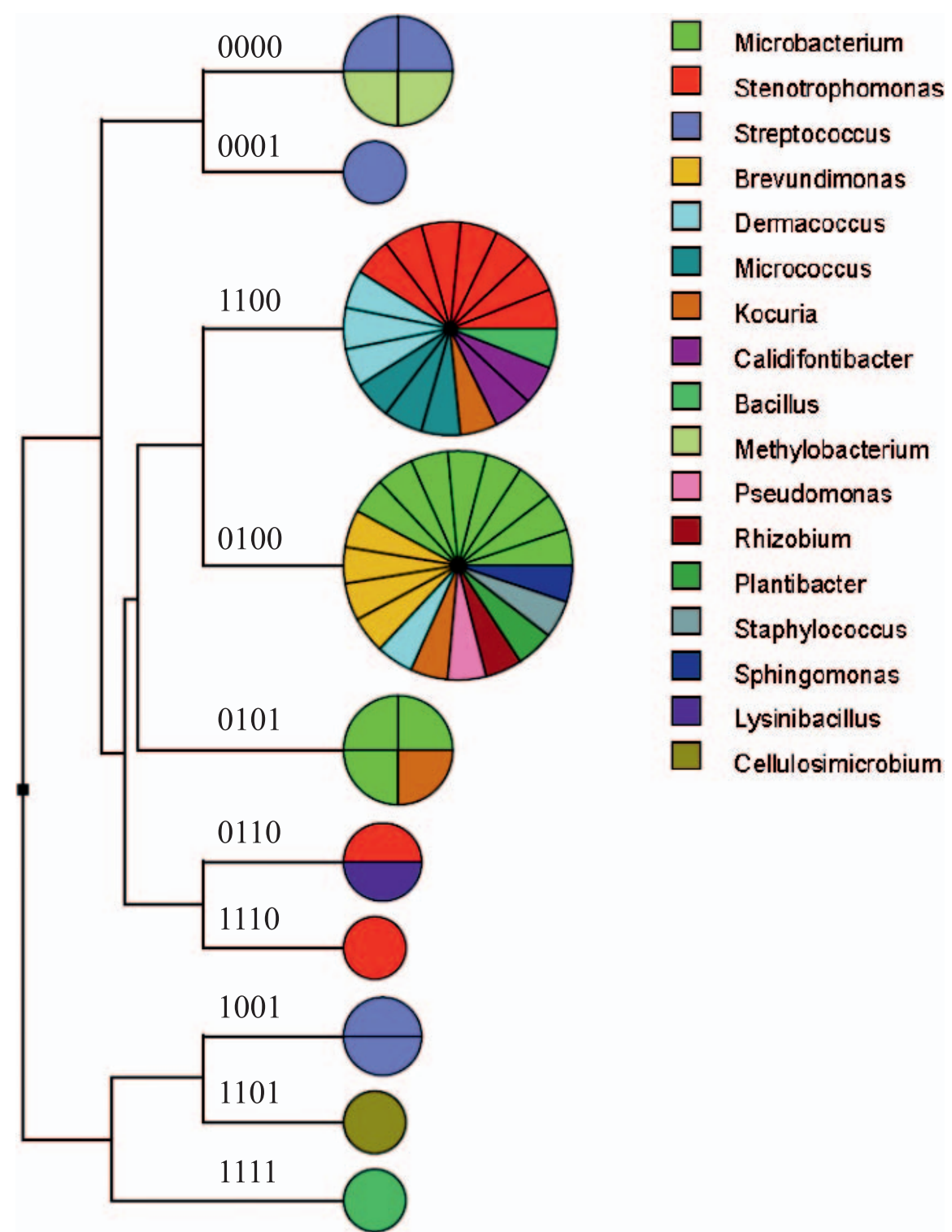

= 55) were identified as Pseudomonas spp. (63.6\%) and Stenotrophomonas spp. (21.8\%). Isolates recovered on PAB and identified to species $(n=48)$ were mostly $S$. rhizophila (18.8\%), P. hunanensis (12.5\%), or Pseudomonas songenensis $(8.3 \%)$.

Spoilage potential of microorganisms on surfaces in food processing companies after C\&D. In total, 278 isolates recovered on PCA $(n=229)$ and PAB $(n=49)$ were evaluated with three (proteolysis, lipolysis, and phospholipolysis) to six spoilage tests to determine the possible impact on food spoilage if cross-contamination from food processing surfaces to food products were to occur. Results of the spoilage tests are presented in Table 2.

(i) Oven food company. In the oven food company, several spoilage profiles were observed; $18.4 \%$ of the evaluated isolates could hydrolyze proteins and lipids, $16.3 \%$ could hydrolyze only lipids, and $16.3 \%$ were negative for all evaluated spoilage tests. All isolates of the dominant Microbacterium spp. $(n=10)$ could degrade lipids. Isolates with the strongest spoilage potential were identified as Bacillus spp. or Serratia spp.

(ii) Two dairy companies. Isolates collected in the dairy companies had two main spoilage profiles: $36.5 \%$ were able to hydrolyze only lipids (dominated by Microbacterium spp. isolates) and $32.7 \%$ were able to hydrolyze lipids and proteins (dominated by Stenotrophomonas spp. isolates) (Fig. 3). Only one strain (Bacillus spp.), which was collected from dairy company 2 , had positive results for all spoilage tests. Other organisms with high spoilage potential were identified as Cellulosimicrobium funkei and S. rhizophila.

(iii) Two meat companies. Two main clusters of isolates with the same spoilage pattern were observed. The biggest cluster, with $20.4 \%$ of the isolates, contained microorganisms that were able to hydrolyze proteins, lipids, and phospholipids. The second group of isolates $(17.5 \%)$ could hydrolyze only lipids. Both groups contained mainly Pseudomonas spp. and Stenotrophomonas spp. For meat 


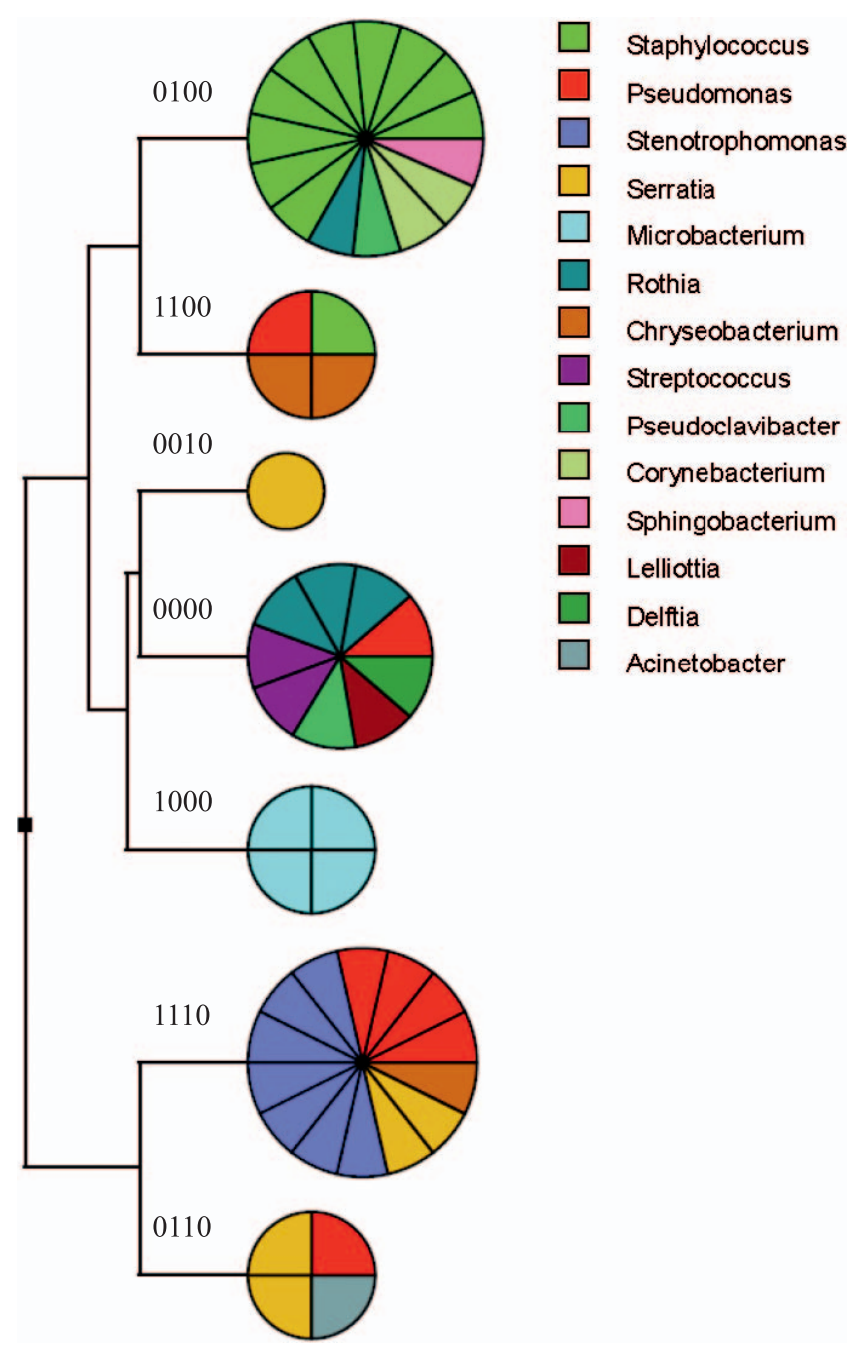

FIGURE 4. Clustering of spoilage results for isolates from an egg processing company based on UPGMA. Results of the four spoilage tests (proteolysis, lipolysis, phospholipolysis, and hydrogen sulfide formation) are shown in order on each branch: 0 indicates a negative result for that test, and 1 indicates a positive result. Groups were based on the genera of the tested isolates.

company 1 , isolates with the strongest spoilage potential were Brochothrix thermosphacta, Kocuria rhizophila, Pseudomonas spp., and S. maltophilia. In meat company 2 , isolates with the strongest spoilage potential were Pseudomonas extremaustralis, Pseudomonas gessardii, Pseudomonas salomonii, and other Pseudomonas species.

(iv) Egg processing company. Isolates mainly clustered into two spoilage groups (Fig. 4). The largest group (29.4\%) was able to hydrolyze lipids and was dominated by Staphylococcus spp. The second group (27.5\%) was able to hydrolyze proteins, lipids, and phospholipids and was dominated by Stenotrophomonas spp. (mostly S. maltophilia) and Pseudomonas spp., but Chryseobacterium spp. and Serratia spp. also were part of this group. A negative result for all spoilage tests was obtained for $17.6 \%$ of the evaluated isolates. (v) Sauce company. The spoilage pattern of isolates was very diverse, but all isolates had a positive result for at least one of the spoilage tests. Isolates with the strongest spoilage potential were identified as Citrobacter youngae, Pseudomonas simiae, and other Pseudomonas species.

(vi) Various food sectors. For all sampled food companies, spoilage properties that were most prevalent among the evaluated isolates were lipolysis $(74.1 \%$ of the tested isolates), proteolysis $(42.5 \%)$, and glucose fermentation $(39.7 \%)$. Overall, $88.5 \%$ of the evaluated isolates had a positive result for one or more spoilage tests. None of the evaluated isolates (all from the egg processing company) were capable of producing hydrogen sulfide. In general, PAB isolates were more capable of hydrolyzing proteins, lipids, or phospholipids than were PCA isolates.

Four main clusters of spoilage potential profiles were noted in the minimum spanning trees considering the results for proteolysis, lipolysis, and phospholipolysis for all isolates (Fig. 5): $30.9 \%$ of the tested isolates could hydrolyze only lipids, $20.9 \%$ were positive for all three tests, $19.8 \%$ were negative for all three tests, and $15.8 \%$ could hydrolyze proteins and lipids. In the biggest cluster, more than $50 \%$ of the isolates were recovered on PCA and were identified as Microbacterium spp., Pseudomonas spp., and Staphylococcus spp. The cluster with isolates positive for all three spoilage tests was dominated by Pseudomonas spp. In general, isolates collected in all the food companies and identified as Bacillus spp., Serratia spp., P. gessardii, and $P$. salomonii had the highest spoilage potential.

Among the five most abundant genera, 43.4\% $(n=76)$ of the Pseudomonas spp. isolates (recovered on PCA and PAB) were able to hydrolyze proteins, lipids, and phospholipids, and $80.3 \%$ of the Pseudomonas isolates produced lipases. However, $13.2 \%$ of Pseudomonas isolates had no spoilage potential based on the tests used. Among the most common Pseudomonas species, P. hunanensis $(n=$ 8) had little spoilage potential, and all $P$. songenensis isolates $(n=3)$ were positive for lipolysis and phospholipolysis. Most of the isolates identified as Microbacterium spp. $(66.7 \%)$ were able to hydrolyze lipids but not proteins or phospholipids $(n=33)$; all Microbacterium isolates had some spoilage potential. Two M. lacticum isolates collected from a dairy company were able to ferment lactose. Three main clusters of spoilage potential profiles were visible in the minimum spanning tree containing all evaluated Stenotrophomonas isolates $(n=35): 42.9 \%$ of these isolates were positive for proteolysis, lipolysis, and phospholipolysis, $25.7 \%$ were positive for proteolysis and lipolysis, and $20 \%$ were positive for only lipolysis. Of the evaluated Stenotrophomonas isolates, $94.3 \%$ (including all S. maltophilia isolates) were able to hydrolyze lipids, and all isolates were positive for at least one of the spoilage tests. All but one of the evaluated Staphylococcus spp. isolates $(n=13)$ had the same spoilage potential, i.e., they were positive only for lipolysis; the remaining Staphylococcus isolate could also hydrolyze proteins. 
FIGURE 5. Clustering of spoilage results for isolates from all seven food companies based on UPGMA. Results of the three spoilage tests (proteolysis, lipolysis, and phospholipolysis) are shown in order on each branch: 0 indicates a negative result for that test, and 1 indicates a positive result. Groups were based on the genera of the tested isolates.

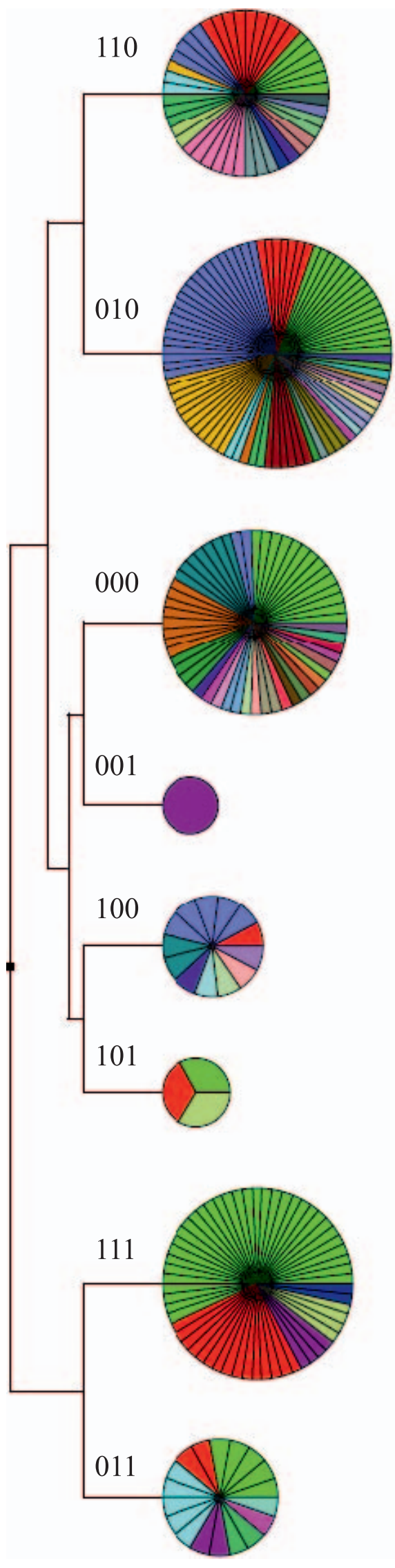

Pseudomonas Stenotrophomonas Microb acterium Staphylococcus Acinetobacter Streptococcus

Rothia

Serratia Kocuria Chryseobacterium Micrococcus Brevundimonas

Pseudoclavibacter Dermacoccus

Bacillus

Lelliotiba

Rherobium

Psychrobacter

Arthrobacter

Sphingobacterium

C alidifontibacter

Corynebacterium

C arnobacterium

Oehrobactrum

Citrobacter

Enterobacter

Brochotrix

Methylobacterium

Leucobacter

C ellulos imicrobium

Lys inib acillus

Elizabethikingia

Pseudochrobactrum Acidovorax

Klebs iella

Lactocoocus

Plantib acter

Sphingomonas

$R$ aoultella

Lactob acillus

$R$ hodococcus

Kurthia

Curtob acterium

Enterococcus

Paenib acillus

$\mathrm{H}$ atnia

Dertia

Pantoae 


\section{DISCUSSION}

Microorganisms in the oven food company. Dominant microorganisms recovered from surfaces in the company that produces ready-to-heat products were mostly Microbacterium spp. and Pseudomonas spp. For this food sector, very little information was found on microbiological characterization of surface contamination. Córdoba et al. (8) reported surface LAB contamination of up to $2.2 \log$ CFU/ $\mathrm{cm}^{2}$ after processing but $<2.0 \log \mathrm{CFU} / \mathrm{cm}^{2}$ on clean surfaces before processing. Several Enterobacteriaceae and LAB were also identified on surfaces in the oven food company in this study. These bacteria can be transferred to the processed food by cross-contamination, and their presence on ready-to-heat products at the time of packaging has been described $(8,28,40)$.

Isolates identified as Enterobacteriaceae or LAB in this study generally had low spoilage potential but were always able to ferment lactose. This characteristic could consequently lead to acidification and a limitation of the shelf life of the oven foods, which often contain milk products. At the time of sampling, food products that were processed on the production line where Lactococcus lactis subsp. cremoris was found on surfaces at high levels $\left(>5 \log \mathrm{CFU} / 100 \mathrm{~cm}^{2}\right)$ also were highly contaminated with LAB 1 day after production (4.40 to $7.18 \log \mathrm{CFU} / \mathrm{g}$ ) and at the end of the shelf life (7.08 to $8.04 \log$ CFU/g) (data not shown, personal communication, 28 November 2017). This finding indicates that there is a high possibility for surface contamination to be transferred to food products and to grow to levels high enough to cause spoilage.

Microorganisms in the two dairy companies. In the dairy companies, isolates were mostly gram-positive bacteria such as Streptococcus spp. and Microbacterium spp. In addition to pseudomonads, bacteria in these two genera are part of the psychrotrophic flora of refrigerated raw milk $(7,26,32)$. Thermophilic Streptococcus spp. can survive the pasteurization process and can form biofilms on dairy equipment (26). Gunduz and Tuncel (17) found several gram-positive and gram-negative biofilm-forming bacteria at various sampling points in dairy processing plants. Among those bacteria, Bacillus spp. and Staphylococcus spp. were also identified in the dairy companies in our study. Schlegelová et al. (35) found S. warneri, a species also found in our study in dairy company 1 , in surfaces samples from a dairy plant after sanitation.

Pseudomonas spp. are the predominant gram-negative species that limit the shelf life at $4^{\circ} \mathrm{C}$ of ultrahigh temperature-treated milk, mainly through the production of heat-stable enzymes $(7,27,36)$. However, only one Pseudomonas isolated was recovered in the dairy companies. Of the genera that were most abundant on dairy equipment, Microbacterium spp. isolates had little spoilage potential (except for degradation of lipids and sometimes lactose fermentation). Dairy company 2 reported that the complaint of one customer led to identification of Microbacterium spp. in the end product. Bacillus spp. are considered dangerous in the dairy industry because of their ability to form endospores, which are resistant to the heat treatments applied during milk processing (7). In addition to toxins, Bacillus spp. can produce spoilage enzymes in food products, as indicated by the results of the spoilage tests performed with the Bacillus isolates obtained in the present study from the dairy companies.

Microorganisms in the two meat companies. In refrigerated food processing environments such as meat companies, specific niches that select for cold-tolerant bacteria are created. Hultman et al. (19) found Pseudomonadales on surfaces in various parts of a sausage processing plant. Genera that are part of this group and were isolated from meat contact surfaces in the present study were identified as Acinetobacter, Psychrobacter, and Pseudomonas. The genus Brochothrix (mostly B. thermosphacta) has been described as very abundant on raw meat $(5,19)$ and was identified in the present study on surfaces that come into contact with unprocessed meat. De Filippis et al. (10) found that Pseudomonas spp., Psychrobacter spp., and B. thermosphacta were the dominant microbiota on environmental swabs. These genera were dominant on spoiled beefsteaks (10) and were previously described as known spoilage organisms on other meat products under various storage conditions (13); their spoilage potential also was identified in the present study. These findings support the hypothesis that bacteria are transferred from surfaces to food products during processing and consequently can lead to spoilage. Stenotrophomonas spp. (mostly S. maltophilia) were often found on surfaces in the two meat companies, which were not described previously in the meat industry. Isolates identified as Stenotrophomonas were variable in their spoilage potential. Most bacterial species found in the two meat companies differed, yet some species ( $K$. rhizophila, S. maltophilia, and P. hunanensis) were found in both companies, indicating their possible role as core species on surfaces after C\&D and in biofilm formation in the meat industry.

Microorganisms in the egg processing company. Microorganisms recovered from surfaces after $C \& D$ in the egg processing company were mostly gram-positive Staphylococcus spp. According to De Reu et al. (12), this is the dominant genus on eggshells. Cross-contamination could be the main reason for finding Staphylococcus at medium to high levels on several surfaces in the egg processing company, despite C\&D. Evaluated Staphylococcus isolates had the ability to hydrolyze lipids. Genera that are also found frequently on eggshells and have been identified in rotten eggs are Alcaligenes, Escherichia, and Pseudomonas $(12,29,31)$. Pseudomonas was identified in the present study on surfaces that come into contact with raw egg contents, and all but one of these isolates had strong spoilage potential that manifested as degradation of lipids, proteins, and phospholipids. However, the pasteurization process should eliminate these eggshell genera and will mostly select for gram-positive heat-tolerant bacteria such as streptococci, enterococci, and Bacillus or other sporeforming genera (4). Bacteria that survive the pasteurization 
process and any contamination that occurs postpasteurization will contribute the most to spoilage.

None of the isolates originating from the egg processing company that were evaluated for their spoilage potential could form hydrogen sulfide, which would result in a typical rotten egg smell.

This company reported that a customer complained about green discoloration of a pasteurized whole egg product. Paenibacillus spp. and Sporosarcina spp. were found in the product. Paenibacillus validus was identified in the present study on surfaces inside raw egg product storage tanks and on a filling head for packaging of pasteurized egg products (recovered on PCA after heat treatment of the sample for $10 \mathrm{~min}$ at $80^{\circ} \mathrm{C}$; data not shown). Paenibacillus spp. and Sporosarcina spp. are known spore-forming genera, which could explain their survival of the pasteurization process and their ability to cause spoilage in food products $(3,16)$.

Microorganisms in the sauce company. Contamination in emulsified sauces (e.g., mayonnaise, which was produced by the participating sauce company) is usually low (37). Because of the low $\mathrm{pH}$ (maximum of 4.5) and the addition of preservatives typical for such food products, pathogens generally do not grow and spoilage organisms usually consist of yeasts, molds, and LAB (mostly lactobacilli) (41). In the present study, isolates collected from food contact surfaces in a sauce company were identified for the first time. The isolates were mostly gram-negative bacteria from the genus Pseudomonas, but some LAB, e.g., Streptococcus spp., also were identified.

In conclusion, generally, gram-negative bacteria, specifically Pseudomonas spp., Enterobacteriaceae, and Acinetobacter spp., are the dominant species on food processing surfaces $(26,30)$. In dairy and dry production environments, gram-positive bacteria are usually the dominant species (30). In the present study, $56.8 \%$ of all the identified isolates collected from the seven food companies were gram-negative bacteria, and $63.8 \%$ of the isolates collected in the dairy companies were gram-positive bacteria. Pseudomonas was the most commonly identified genus $(20.5 \%)$ from all the food companies. Pseudomonas spp. also play an important role in spoilage of food stored at low temperatures (30). In the present study, $86.8 \%$ of the evaluated Pseudomonas isolates had some kind of spoilage potential based on the results of laboratory tests. In addition to Pseudomonas, the genera most often found were Microbacterium (12.2\%) and Stenotrophomonas (9.2\%). These bacteria have not been previously described as predominantly present on surfaces in food processing environments but were collected from several of the sampled food companies. Their presence at medium to high levels after C\&D on surfaces in various food companies and their spoilage potential suggests that Microbacterium, Stenotrophomonas, and Pseudomonas may play important roles in residual bacterial contamination of the food processing environment and in food spoilage.
However, most of the other genera identified among the dominant microbiota $(60 \%)$ were company specific.

Of the isolates evaluated in this study, $88.5 \%$ seemed to have some spoilage potential. However, further investigation is needed to determine whether these bacteria (i) can be transferred from the surface to the food product, (ii) can survive and grow in food products (5), and (iii) can consequently cause spoilage. Isolates also can differ in expression of these spoilage characteristics (11).

The microbial safety of food products depends on the quality of the raw ingredients and on hygienic practices in food processing facilities. Surface contamination with microorganisms plays an important role in cross-contamination of end products and could eventually cause foodborne illness or early food spoilage. Unfortunately, many food companies have little to no information about the types of microbial contaminants or spoilage organisms in their facilities. In the present study, surface contamination was mapped for several food companies from different food sectors, and the possible role of this contamination in food spoilage was investigated. This information will be useful to food companies for better understanding their contamination and spoilage problems. Microorganisms present in biofilms on surfaces are difficult to eliminate, leading to persistent contamination, and the presence of biofilms can enhance the attachment of pathogenic bacteria (19). These factors highlight the importance of an optimized and effective $\mathrm{C} \& \mathrm{D}$ procedure that can reduce or eliminate the bacteria found in this study. Further research by our group will focus on the biofilm forming capacity of the residual bacteria after C\&D and the development of optimal C\&D protocols to provide more insight into the role of biofilms in food contamination and food spoilage.

\section{ACKNOWLEDGMENTS}

We thank the participating food companies for their generous and constructive cooperation. This work would not have been possible without the help of Eline Dumoleijn. We also extend many thanks to Ann Van De Walle, Sofie De Vlam, and Elly Engels for their assistance. This research is funded by Flanders' Food (KILLFILM project).

\section{REFERENCES}

1. Adator, E. H., M. Cheng, R. Holley, T. McAllister, and C. NarvaezBravo. 2018. Ability of Shiga toxigenic Escherichia coli to survive within dry-surface biofilms and transfer to fresh lettuce. Int. J. Food Microbiol. 269:52-59.

2. AlZaabi, S. E., and M. Khan. 2017. A study on foodborne bacterial cross-contamination during fresh chicken preparation. Arab J. Nutr. Exerc. 2:128-138.

3. An, S. Y., T. Haga, H. Kasai, K. Goto, and A. Yokota. 2007. Sporosarcina saromensis sp. nov., an aerobic endospore-forming bacterium. Int. J. Syst. Evol. Microbiol. 57:1868-1871.

4. Baron, F., and S. Jan. 2011. Egg and egg product microbiology, p. 330-350. In Y. Nys, M. Bain, and F. Van Immerseel (ed.), Improving the safety and quality of eggs and egg products. Woodhead, Sawston, UK.

5. Borch, E., M.-L. Kant-Muermans, and Y. Blixt. 1996. Bacterial spoilage of meat and cured meat products. Int. J. Food Microbiol. 33:103-120.

6. Brooks, J. D., and S. H. Flint. 2008. Biofilms in the food industry: problems and potential solutions. Int. J. Food Sci. Technol. 43:21632176. 
7. Coorevits, A. 2011. Pseudomonads and bacilli as important spoilage organisms in the dairy industry - a taxonomic study. Ph.D. thesis. University of Ghent, Ghent, Belgium.

8. Córdoba, M. G., J. J. Córdoba, and R. Jordano. 1999. Microbiological hazards during processing of croquettes. J. Food Saf. 19:1-15.

9. Dantas, S. T. A., B. F. Rossi, E. C. R. Bonsaglia, I. G. Castilho, R. T. Hernandes, A. Fernandes, and V. L. M. Rall. 2018. Crosscontamination and biofilm formation by Salmonella enterica serovar Enteritidis on various cutting boards. Foodborne Pathog. Dis. 15:8185 .

10. De Filippis, F., A. La Storia, F. Villani, and D. Ercolini. 2013. Exploring the sources of bacterial spoilers in beefsteaks by cultureindependent high-throughput sequencing. PLoS One 8:e70222.

11. De Jonghe, V., A. Coorevits, J. De Block, E. Van Coillie, K. Grijspeerdt, L. Herman, P. De Vos, and M. Heyndrickx. 2010. Toxinogenic and spoilage potential of aerobic spore-formers isolated from raw milk. Int. J. Food Microbiol. 136:318-325.

12. De Reu, K., W. Messens, M. Heyndrickx, T. B. Rodenburg, M. Uyttendaele, and L. Herman. 2008. Bacterial contamination of table eggs and the influence of housing systems. Worlds Poult. Sci. J. 64:5-19.

13. Doulgeraki, A. I., D. Ercolini, F. Villani, and G. J. Nychas. 2012. Spoilage microbiota associated to the storage of raw meat in different conditions. Int. J. Food Microbiol. 157:130-141.

14. European Food Safety Authority, European Centre for Disease Prevention and Control. 2017. The European Union summary report on trends and sources of zoonoses, zoonotic agents and food-borne outbreaks in 2016. EFSA J. 15:5077

15. Giaouris, E., E. Heir, M. Hébraud, N. Chorianopoulos, S. Langsrud, T. Moretro, O. Habimana, M. Desvaux, S. Renier, and G.-J. Nychas. 2014. Attachment and biofilm formation by foodborne bacteria in meat processing environments: causes, implications, role of bacterial interactions and control by alternative novel methods. Meat Sci. 97:289-309.

16. Grady, E. N., J. MacDonald, L. Liu, A. Richman, and Z.-C. Yuan. 2016. Current knowledge and perspectives of Paenibacillus: a review. Microb. Cell Fact. 15:1-18.

17. Gunduz, G. T., and G. Tuncel. 2006. Biofilm formation in an ice cream plant. Antonie Leeuwenhoek 89:329-336.

18. Habimana, O., E. Heir, S. Langsrud, A. W. Åsli, and T. Møretrø. 2010. Enhanced surface colonization by Escherichia coli O157:H7 in biofilms formed by an Acinetobacter calcoaceticus isolate from meat-processing environments. Appl. Environ. Microbiol. 76:45574559.

19. Hultman, J., R. Rahkila, J. Ali, J. Rousu, and K. J. Björkroth. 2015. Meat processing plant microbiome and contamination patterns of cold-tolerant bacteria causing food safety and spoilage risks in the manufacture of vacuum-packaged cooked sausages. Appl. Environ. Microbiol. 81:7088-7097.

20. Kim, O.-S., Y.-J. Cho, K. Lee, S.-H. Yoon, M. Kim, H. Na, S.-C. Park, Y. S. Jeon, J.-H. Lee, H. Yi, S. Won, and J. Chun. 2012. Introducing EzTaxon-e: a prokaryotic 16S rRNA gene sequence database with phylotypes that represent uncultured species. Int. J. Syst. Evol. Microbiol. 62:716-721.

21. Kuda, T., A. Nakano, H. Takahashi, and B. Kimura. 2016. Effect of the quantities of food residues on the desiccation resistance of spoilage lactic acid bacteria adhered to a stainless steel surface. Food Control 68:40-44.

22. Kusumaningrum, H. D., G. Riboldi, W. C. Hazeleger, and R. R. Beumer. 2003. Survival of foodborne pathogens on stainless steel surfaces and cross-contamination to foods. Int. J. Food Microbiol. 85:227-236.

23. Lindsay, D., and A. von Holy. 2006. What food safety professionals should know about bacterial biofilms. Br. Food J. 108:27-37.
24. Maes, S., S. Nguyen Huu, M. Heyndrickx, S. Van Weyenberg, A. Verplaetse, T. Vackier, I. Sampers, K. Raes, and K. De Reu. 2017. Evaluation of two surface sampling methods for microbiological and chemical analyses to assess the presence of biofilms in food companies. J. Food Prot. 80:2022-2028.

25. Maes, S., T. Vackier, S. Nguyen Huu, M. Heyndrickx, H. Steenackers, I. Sampers, K. Raes, A. Verplaetse, and K. De Reu. Occurrence and characterization of biofilms in drinking water systems of broiler houses. Submitted for publication.

26. Marchand, S., J. De Block, V. De Jonghe, A. Coorevits, M. Heyndrickx, and L. Herman. 2012. Biofilm formation in milk production and processing environments: influence on milk quality and safety. Compr. Rev. Food Sci. Food Saf. 11:133-147.

27. Marchand, S., K. Heylen, W. Messens, K. Coudijzer, P. De Vos, K. Dewettinck, L. Herman, J. De Block, and M. Heyndrickx. 2009. Seasonal influence on heat-resistant proteolytic capacity of Pseudomonas lundensis and Pseudomonas fragi, predominant milk spoilers isolated from Belgian raw milk samples. Environ. Microbiol. 11:467482.

28. Masegosa, R., J. Delgado-Adámez, R. Contador, F. Sánchez-Íñiguez, and R. Ramírez. 2013. Effect of processing by hydrostatic high pressure of two ready to heat vegetable meals and stability after refrigerated storage. Food Sci. Technol. Int. 20:605-615.

29. Mayes, F. J., and M. A. Takeballi. 1983. Microbial contamination of the hen's egg: a review. J. Food Prot. 46:1092-1098.

30. Møretrø, T., and S. Langsrud. 2017. Residential bacteria on surfaces in the food industry and their implications for food safety and quality. Compr. Rev. Food Sci. Food Saf. 16:1022-1041.

31. Neira, C., A. Laca, A. Laca, and M. Díaz. 2017. Microbial diversity on commercial eggs as affected by the production system: a first approach using PGM. Int. J. Food Microbiol. 262:3-7.

32. Porcellato, D., M. Aspholm, S. B. Skeie, M. Monshaugen, J. Brendehaug, and H. Mellegård. 2018. Microbial diversity of consumption milk during processing and storage. Int. J. Food Microbiol. 266:21-30.

33. Price, M. F., I. D. Wilkinson, and L. O. Gentry. 1982. Plate method for detection of phospholipase activity in Candida albicans. Sabouraudia 20:7-14.

34. Rawat, S. 2015. Food spoilage: microorganisms and their prevention. Asian J. Plant Sci. Res. 5:47-56.

35. Schlegelová, J., V. Babák, M. Holasová, L. Konstantinová, L. Necidová, F. Šisák, H. Vlková, P. Roubal, and Z. Jaglic. 2010. Microbial contamination after sanitation of food contact surfaces in dairy and meat processing plants. Czech J. Food Sci. 28:450-461.

36. Simões, M., L. C. Simões, and M. J. Vieira. 2010. A review of current and emergent biofilm control strategies. LWT Food Sci. Technol. 43:573-583.

37. Smittle, R. B. 1977. Microbiology of mayonnaise and salad dressing: a review. J. Food Prot. 40:415-422.

38. Stellato, G., F. De Filippis, A. La Storia, and D. Ercolini. 2015. Coexistence of lactic acid bacteria and potential spoilage microbiota. Appl. Environ. Microbiol. 81:7893-7904.

39. Strandén, A., R. Frei, and A. F. Widmer. 2003. Molecular typing of methicillin-resistant Staphylococcus aureus: can PCR replace pulsedfield gel electrophoresis? J. Clin. Microbiol. 41:3181-3186.

40. Stratakos, A., M. Linton, M. Patterson, and A. Koidis. 2015. Effect of high-pressure processing on the shelf life, safety and organoleptic characteristics of lasagne ready meals during storage at refrigeration and abuse temperature. Innov. Food Sci. Emerg. Technol. 30:1-7.

41. Vermeulen, A. 2008. Microbial stability and safety of acid sauces and mayonnaise-based salads assessed through probabilistic growth/ no growth models. Ph.D. thesis. University of Ghent, Ghent, Belgium. 